\title{
Intergenerational mobility and school inequality in the US
}

Children of different income groups attend schools of diferent quality. To understand opportunity contributes to and human capital, Professor Jean Hindriks, Head of the Economics School of Louva at UCLouvain, Belgium, and Dr Andreu Arenas, Assistant the University of Barcelona, Beckertomes-Solon parentinclude unequal opportunity in their modelling of

parental investment into how unequal school Professor of Economics at have extended the classical children's education and intergenerational mobility.

cross neighbourhoods in the US, the best schools are left behind without
there are noticeable differences in
the same opportunities there are noticeable differe
intergenerational mobility.

High-mobiry areas, where social position Dr Jean Hindriks, Professor of Economics tends to change from one generation

segregation, less income inequality,

and better primary schools than areas

with lower intergenerational mobility.

In addition to the differences in family

characteristics across neighbourhoods, it

has been shown that these correlations are caused by the neighbourhoods themselves. Of particular interest is the observation that upward mobility in educational attainment has significant links to local public education policy.

The importance of good schooling has increased with technological change. The ensuing demand for education is resulting in more socially segregated family to live in the best community they can afford, where their children receive the best education possible so that they can compete in a global and digital economy. Those who cannot afford to move into communities with

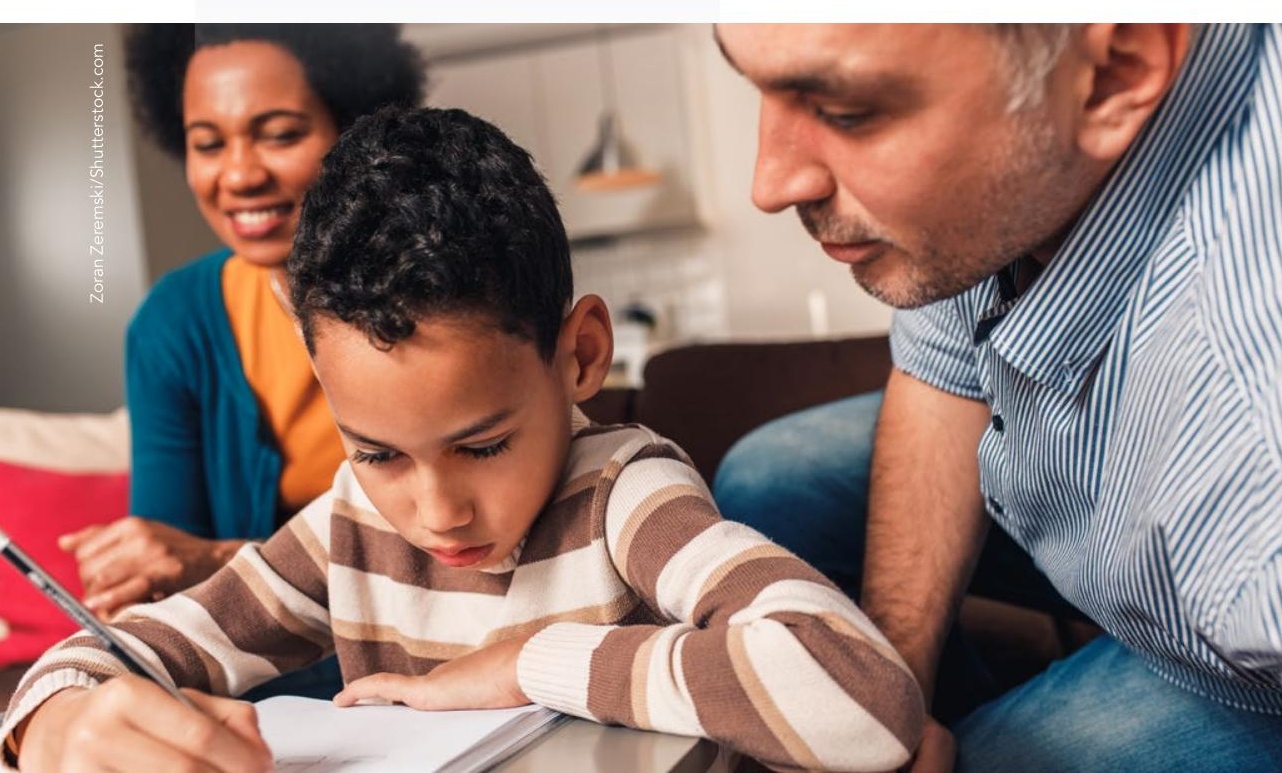

and Head of the Economics School of Louvain at UCLouvain, Belgium, and Dr Economics at the University of Barcelon have incorporated these recent empirical insights in the development of their theoretical framework on intergenerational mobility. To understand how unequal school opportunity contributes to differences in social children's education and intergenerationa mobility and extended the classical transmission model.

\section{UNIFORM SCHOOL SYSTEM} Models based on a uniform schoo system, such as the Becker-Tomes-
Solon model, assume that parents a uniform tendency to invest in their quality parents are willing to invest more. While the model of human capital (the value or cost of the skills, knowledge, and experience possessed by an individual or population) and school quality are standard, this involves a complementarity between parental investment and school quality. Empirical research has shown that UK families living in neighbourhoods with better school quality invest relatively more Head Start (a program providing early and parent involvement support for

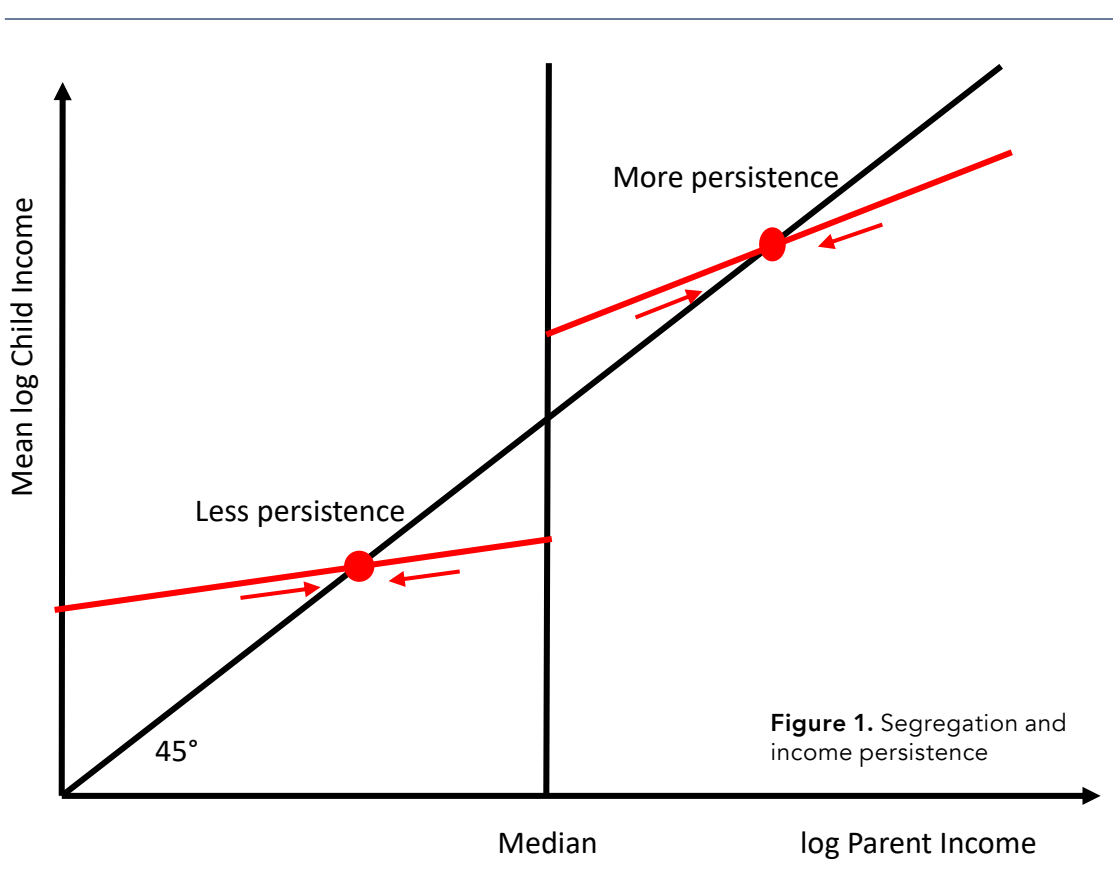
mobility and human capital, they have built a model of parental investment into Becker-Tomes-Solon parent-child children and when schools are of higher in their children's education. Furthermore
in the US, parents of children attending childhood education, health, nutrition their investment in education partly schools, offering in turn higher returns to those investments, while low-income parents invest less because of poorparenting gap, creating a "double dow on inequality. As a result, unequal schoo opportunity increases income persistence at the top and reduces overall income mobility. However, there is a tradeoff also increases average human capital, an efficiency gain (in terms of increased skills and knowledge) stemming from positive
Median

log Parent Income

low-income families) were found to have greater involvement with their children than other low-income parents.

UNEQUAL SCHOOL OPPORTUNITY PARENTAL INVESTMENT Intuitively, we would expect to find that schools and invest a highd high-qual iy schools and invest a higher proportion
of their income in education, and low-income families attend low-quality schools and invest a smaller proportion of their income. Prof Hindriks and Dr Arenas argue that unequal school opportunity exacerbates the parenting gap by makng

calibrated their model to assess the magnitude of this mobility-efficiency chel policies have more effect on mobility than on efficiency.

\section{HUMAN CAPITAL}

estment can increase or decrease under unequal schoo opportunity, the research suggests that average human capital always increases because of the complementarity
between school productivity and parental investment that shapes human capital. In the high-income group, school segregation was observed to increase parental investment where the productivity of investment was also higher. Likewse, in reduced invst as

INTERGENERATIONAL ELASTICITY The researchers calculate the

intergenerational elasticity of income as Besides inheritance, parents pass their economic status to their children throug education. They showed that when there is more variation in parental income at the top of the income distribution unequal opportunity to their model. This and an unequal probability of access to the best schools. They explain how unequal school opportunity increases it more attractive for families with a higher al the bottom, which is the case

i.e. the difference Unequal school opportunity exacerbates among high-income between high and low parenting the parenting gap by making it more better school quality 'quality' (involvement, attractive for high-income families to and the increasing investment,

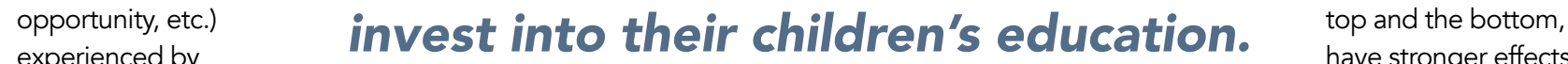
experienced by
children. This

prompted their analysis of the dynamic the effects of unequat schol sportunity education. High income familes in's on parental investment, human capital,

School inequality describes the disparity in school quality across neighbourhoods. Unequal access involves the relationship between parental income and access to the best schools. This is linked to educational policies promoting equality of opportunity with equal access to schools for children from any neighbourhood, including priorities in school choice mechanisms, leading to positive assortative matching with the preferen matching of high-quality schools with education. High-income families increase because unequal school opportunity mersistence among lowine decrease families. This leads to a decrease in intergenerational mobility overall.

UNEQUAL OPPORTUNITY AND SORTING DECISIONS

The simulations disclosed that the shape the positive sorting decisions. This results in children of high-income parents being allocated high-quality schools. To understand the significance of this trade-off, the researchers calibrated the model to match the US income distribion. Then they simulated the effects of de-segregation and schoo disclosed that equal opportunity policies complementarity between school quality and parental investment can potentially 


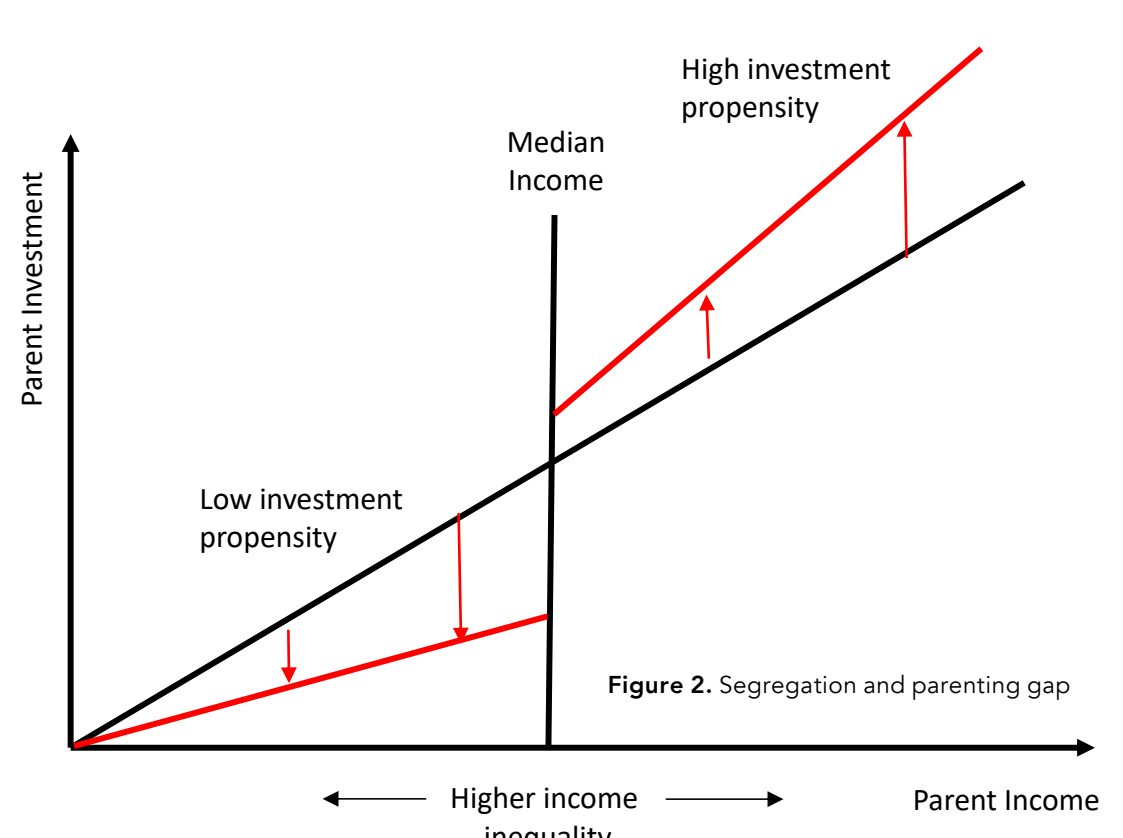

inequality

produce high intergenerational mobility gains at a relatively small efficiency cost.

\section{MODEL SIMULATIONS}

\section{AND RESULTS}

The interaction between income inequality and unequal school This facilitated a study of the effect of simultaneous changes in school inequality, segregation, and income inequality. This analysis revealed a multifaceted interpretation of school quality and its inequality. The researchers found a variety of reasons for the differences in school productivity - including differences in school inputs, peers, the family, and the surrounding conmunity. These finding of school inequality as a natral resut of school segregation, or a broad neighbourhood effect.

The simulations also revealed that independent increases in income inequality do not necessarily lead to an increase in intergenerational persistence. Increases in income inequality, when accompanied with increases in unequal school opportunity, however, do result in a positive correlation between inequality and persistence. This interaction of income inequality with school inequalty and segregation reveals that income inequality reduces social mobility and suggests that unequal school opportunity plays a significant part in the Council Economic Advisers. Named after Francis Scott Fitzgerald's book, he Great Gatsby, in which the main family, made a lot of money but failed to escape from his past The book closes down as, "So we beat on, boats against the current, borne back ceaselessly into the past." The Great Gatsby Curve can be used to illustrate the illusions of educational mobility in areas of highincome inequality.

EQUALITY OF OPPORTUNITY Professor Hindriks and Dr Andreu Arenas' model combines unequal school quality together with an unequal access to

high-quality schools that is linked to social segregation. Income dispersion tends to be higher at the top, so in most cases unequal school opportunity Having cal brated theina mobility. their simulations suggest that the social mobility costs of school inequality and segregation are large when compared

with the gain in human capital. Moreove The Great Gatsby curve illustrates the of wealth in one generation and the ability of those in the next generation to

These simulations disclosed that equal opportunity policies produce high intergenerational mobility gains at a relatively small efficiency cost.

move up the economic ladder compared equality of opportunity through school to their parents. The curve was equalisation and desegregation policies introduced by Professor Alan Krueger, can have positive effects on mobility with

Income inequality interactions

Changes in $\phi$, small elasticity of $p$ and $\kappa \quad$ Changes in $\phi$, large elasticity of $p$ and $\kappa$

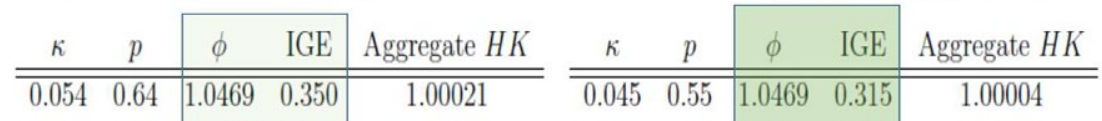

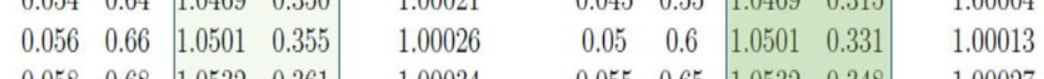
$\begin{array}{lllllllllll}0.058 & 0.68 & 1.0532 & 0.361 & 1.00034 & & 0.055 & 0.65 & 1.0532 & 0.348 & 1.00027\end{array}$ \begin{tabular}{ll|l|l|l|l|l|l|l|l|}
0.06 & 0.7 & 1.056 & 0.366 & 1.00041 & 0.06 & 0.7 & 1.0561 & 0.366 & 1.00040 \\
\hline
\end{tabular} \begin{tabular}{ll|l|l|l|l|l|l|l|l|}
0.062 & 0.72 & 1.0588 & 0.372 & 1.00048 & 0.065 & 0.75 & 1.0588 & 0.386 & 1.00057 \\
\hline
\end{tabular}

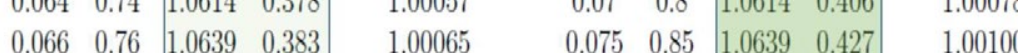
Corr ( inequality, IGE) $>0$ = Gatsby Curve

K-school quality gap
p-school segregation $\quad \begin{gathered}\text { - income inequality } \\ \text { IGE- intergenerational lelasticity }\end{gathered} \quad H K$-human capital level Figure 3. Gatsby simulation. Left panel low interaction between income inequality and unequa
school opportunities. Right panel high interaction between income inequality and unequal

\section{Behind the Research} (f)

Prof Jean Hindriks

W: www.jeanhindriks.com in jean-hindriks-aa894014

Research Objectives

Prof Hindriks and Dr Arenas developed a theoretical framework on intergenerational mobility.

\section{Detail}

\section{Address}

Jean Hindrik

CORE, Université catholique de Louvain

Voie du Roman Pays 34, 1348 Louvain-la-Neuve Belgium

Andreu Arenas

University of Barcelona School of Economics

JM Keynes 1-11, 08034, Barcelon

Spain

Jean Hindriks is a Professor of Economics and Head of the Economics School of Louvain at UCLouvain (Belgium), and touning

Andreu Arenas is an Assistant Professor of Economics

Andreu Arenas is an Assistant Professor of Economics

at the University of Barcelona and a researcher at the

Barcelona Institute of Economics (IEB). He obtained

$\mathrm{PhD}$ from the European University Institute (Italy).

Funding

Move In Louvain "incoming post-doc fellowships"

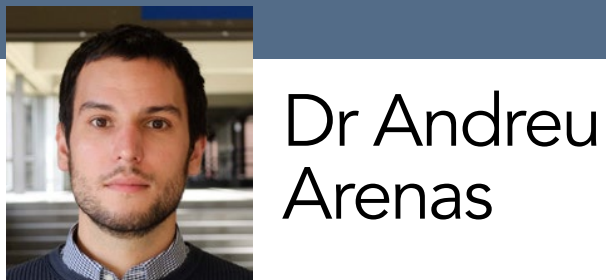

b.edu T: +34650513478 W: www.andreuarenas.eu ifin andreu-arenas-jal-58a60162

References

Arenas, A. \& Hindriks, J. (2021). Intergenerational Mobility and Unequal School Opportunity

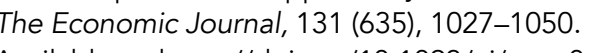

Available at. htps///doiog/10.1093/ej/ueaa062

Chetty, R., Friedman, J.N., Saez, E., Turner, N. \& Yagan, D. (2020). Income Segregation and Intergenerational Mobility
Across Colleges in the United States. The Quarterly Journal of Economics, 135 (3), 1567-1633.

\section{Personal Response}

\section{What motivated you to extend the classical} Becker-Tomes-Solon parent-child trans
model to include unequal opportunity?

II Recent work by Raj Chetty and co-authors shows the importance for income and education of growing up in good neighbourhoods, outlining the effects of social segregation. Moreover, parents increasingly use schooling
to transmit their status to their offspring, which is especially important in a context of rapid technological change. In
addition, there is a negative relationship across countries between inequality and social mobility (the Gatsby curve), which is not implied by the classical transmission models. We thought that integrating these insights would give us between newesulits and implications of the interaction turned out that unequal school opportunity bridges the gap between inequality and mobility.

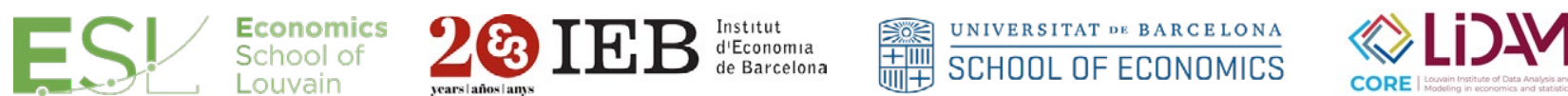

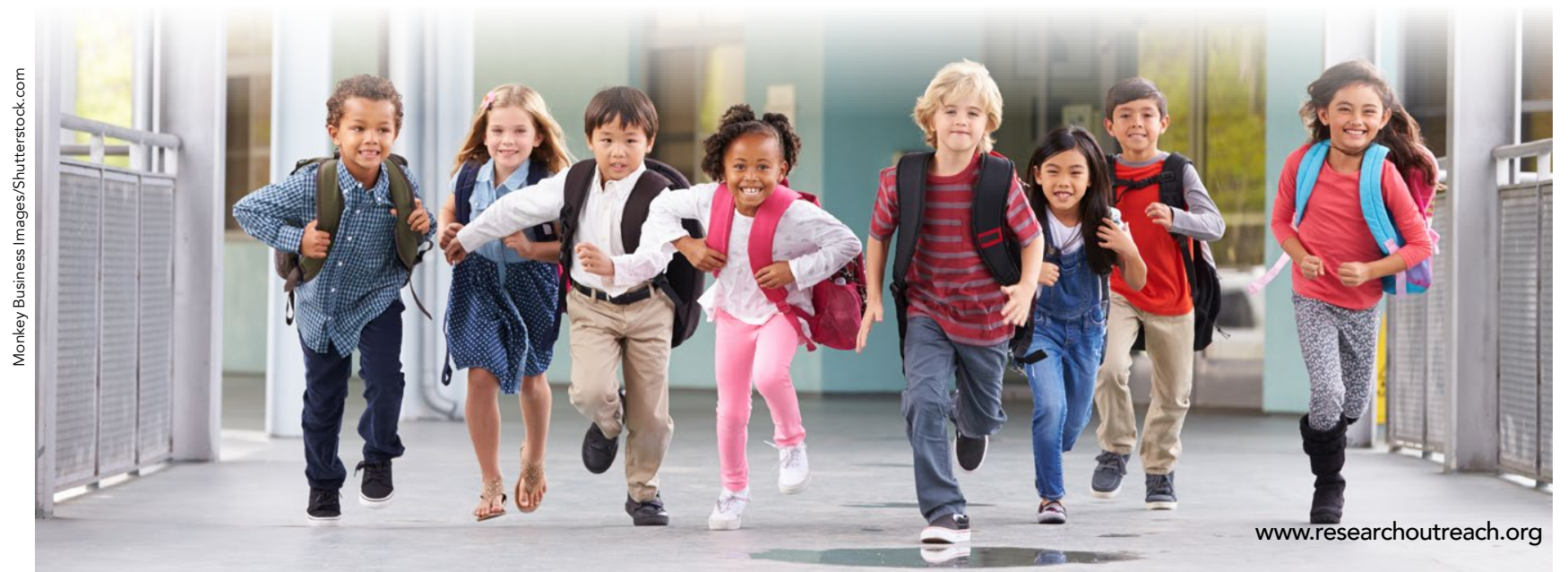

